\title{
Antepartum urinary tract infection and postpartum depression in Taiwan - a nationwide population-based study
}

Jui-Ming Liu ${ }^{1,2,3 \dagger}$, Feng-Hsiang Chiu ${ }^{4,5+}$, Yueh-Ping Liu ${ }^{6}$, Shu-Pin Chen ${ }^{7}$, Hsun-Hao Chan ${ }^{8}$, Jing-Jung Yang ${ }^{9,10}$, Fung-Wei Chang ${ }^{11^{*}}$ and Ren-Jun Hsu ${ }^{3,12,13^{*}}$ (D)

\begin{abstract}
Background: Urinary tract infections (UTIs) are among the most common bacterial infections in pregnant women due to anatomic and physiologic changes in the female urinary tract during pregnancy, and antepartum UTIs can cause adverse pregnancy outcomes that may induce mental stress. There have only been a few studies, however, investigating antepartum UTIs and mental stress. As such, the present study was conducted in order to investigate the association between antepartum UTIs and postpartum depression (PPD).

Methods: We used data from the 2000-2013 National Health Insurance Research Database (NHIRD) of Taiwan. Data regarding a total of 55,087 singleton pregnancies was utilized, including data regarding 406 women who were newly diagnosed with PPD in the first 6 months postpartum. The associations between PPD and antepartum UTIs or other risk factors were examined by multiple logistic regression analysis.

Results: The logistic regression analysis results indicated that PPD was associated with antepartum UTIs (adjusted odds ratio [aOR] 1.27; 95\% confidence interval [CI] (1.07-1.65). Furthermore, the risk of PPD was higher in women with an upper antepartum UTI (aOR $2.97(1.31,6.77)$ than in those with a lower antepartum UTI (aOR 1.21 $(1.02,1.58))$.

Conclusions: Antepartum UTIs, particularly upper antepartum UTIs, are significantly associated with PPD. This information may encourage physicians to pay greater attention to the mental health of women who have suffered upper UTIs during their pregnancies.
\end{abstract}

Keywords: Urinary tract infection, National health insurance research database, Postpartum depression, Female

\section{Background}

Previous epidemiological studies have reported that postpartum depression (PPD) occurs in approximately $10-15 \%$ of women after delivery [1-3]. PPD is defined in the fifth edition of the Diagnostic and Statistical Manual of Mental Disorders (DSM-V) [4] as a major depressive episode occurring during pregnancy or in the 4 weeks following delivery. However, PPD usually occurs in the first 6 months after delivery [5, 6]. A recent study of postnatal women in the UK and Taiwan showed that

\footnotetext{
* Correspondence: doc30666@gmail.com; hsurnai@gmail.com

${ }^{\dagger}$ Equal contributors

${ }^{11}$ Superintendent, Tri-Service General Hospital Penghu Branch, National

Defence Medical Center, Penghu Branch, Taiwan

${ }^{3}$ Graduate Institute of Life Sciences, National Defense Medical Center, Taipei,

Taiwan

Full list of author information is available at the end of the article
}

$19 \%$ of Taiwanese women and 18\% of British women reported experiencing PPD [7].

During pregnancy, women experience substantial physiological and psychological changes. These changes may lead postpartum depressive mood. Previous studies have highlighted numerous risk factors associated with PPD including physical, psychological, obstetric, pediatric, socio-demographic, and cultural factors [8, 9].

Pregnancy also causes anatomic and physiologic changes to the female urinary tract. Urinary tract infections (UTIs) are among the most common bacterial infections during pregnancy [10], with approximately $2-10 \%$ of pregnant women experiencing a UTI [11]. Antepartum UTIs are associated with some adverse pregnancy outcomes [12] and are also one of the major causes of antepartum admissions [13]. 
To the best of our knowledge, however, there have been very few reports on the relationship, if any, between antepartum UTIs and PPD. As such, the present population-based study sought to (1) determine whether there is a relationship between antepartum UTIs and PPD and (2) determine whether different locations of antepartum UTIs (that is, in the upper or lower urinary tract) result in different effects on the mental health of pregnant women.

\section{Methods}

\section{Data source and collection}

We used the National Health Insurance Research Database (NHIRD) for this population-based study. The NHIRD is a database collected by the National Health Insurance (NHI) program of Taiwan, which is a unique health insurance system covering almost all the citizens of Taiwan. The NHI program was begun in 1995 and provided coverage for 99.9\% of the 23 million people in Taiwan as of 2013 [14]. The NHIRD is a large-scale database that contains outpatient and inpatient medical information about the patients included in the database, including information on their medication use, surgical procedures, intervention procedures, and clinical prescriptions $[15,16]$. At present, there are more than 2000 published studies that have utilized data included in this database [17]. The present retrospective population-based study used a subdataset of the NHIRD called the Longitudinal Health Insurance Database 2000 (LHID 2000) that included data from January 2000 to December 2013. The LHID 2000 contains 1 million people who were randomly selected from the total of 23 million residents included in the NHIRD in 2000 [18, 19]. The disease diagnoses of the people included in the database were made according to the International Classification of Diseases, 9th revision, Clinical Modification (ICD-9-CM).

\section{Study population}

The study population was selected from the LHID 2000 covering the period from January 2000 to December 2013. The selection of participants in this study is shown in Fig. 1. There were 73,829 singleton pregnancies among the database cohort during the study period. The exclusion criteria were as follows (1) women with delivery before Dec 31st 2000 or after July 31st 2013 ( $n=11,480)$; (2) women who were younger than 20 years old $(n=2571)$; (3) women who had a previous history of major depressive disorder $(n=2449)$; and (4) women with a follow-up period of less than 6 months $(n=55)$. In Taiwanese civil law, people in their twenty years of age are adult. We chose adult women in our study with approval by the Institutional Review Board. We selected women identified as having PPD according to a medical record of a PPD diagnosis made by a psychiatrist and by the use of antidepressants in the first 6 months after delivery (ICD-9-CM: 309, 311, 296.2, 296.3, 296.5, 300.4).

Each UTI was diagnosed by collecting a clean-voided, midstream urine sample for urinalysis and urine culture. A positive urine culture was defined by the isolation of at least one single microorganism with $>10,000$ colonies/ $\mathrm{mL}$. An upper UTI was diagnosed according to physical examination, urinalysis, and urine culture results, with positive physical examination findings including flank pain, fever, chills, anorexia, nausea, and vomiting. The diagnosis of a lower UTI was also made via physical examination, urinalysis, and urine culture results, with the typical manifestations of a lower UTI including dysuria, frequency, urgency, and suprapubic pain.

\section{Variables}

Variables were selected based on clinical manifestations or complications during pregnancy. We retrospectively investigated different variables in women with or without PPD. In this study, antepartum UTIs were grouped into two categories: upper and lower UTIs. An upper UTI consists of an infection of the renal parenchyma and pelvicaliceal system. This includes cases of pyelonephritis, pyelitis, and perirenal infection or abscess (ICD-9-CM: 590.1, 590.2, 590.8, 590.9). Lower UTI infections are located in the lower urinary tract and include cystitis and urethritis (ICD-9-CM: 595.0, 595.1, 595.2, 595.3, 595.4, 595.8, 595.9, 597.8, 599.0). Additional factors of antepartum, peripartum, and postpartum complications that are related to PPD, according to a previous study [20], were also analyzed, including antepartum hemorrhage (ICD-9-CM: 641.8, 641.9), eclampsia or pre-eclampsia (ICD-9-CM: 642.4, 642.5, 642.6), premature separation of placenta (ICD-9-CM: 641.2), placenta previa (ICD-9-CM: 641.0, 641.1), oligohydramnios (ICD-9-CM: 658), polyhydramnios (ICD-9-CM: 657), poor fetal growth (ICD-9-CM: 656.5), excessive fetal growth (ICD-9-CM: 656.6), cervical incompetence (ICD-9-CM: 654.5), premature birth (ICD-9-CM: 644), chronic pulmonary disease (ICD-9-CM: 490-492, 494,496), hypertension (ICD-9-CM: 401.1401.9), hypertension-complicated pregnancy (ICD-9CM: 642.0, 642.1, 642.2, 642.3, 642.9), diabetes complicating pregnancy childbirth (ICD-9-CM: 648.0), hyperlipidemia (ICD-9-CM: 272.4), heart disease (ICD-9-CM: 393-398, 402, 404.0, 404.1, 404.9, 410-414, 415.0, 416.1, 416.8, 416.9, 420-429), anemia (ICD-9- CM: 280-285), cerebrovascular disease (ICD-9-CM: 430-438), Parkinson disease (ICD-9CM: 332), epilepsy (ICD-9-CM: 345), tuberculosis (ICD-9CM: 011,012), asthma (ICD-9-CM: 493), chronic kidney disease (ICD-9-CM: 585,586,588). The monthly incomes of the study population, as per insurance information, were divided into four groups: $<20,000,20,000-40,000,40,000$ 60,000 , and $\geq 60,000$ new Taiwan dollars [21]. 


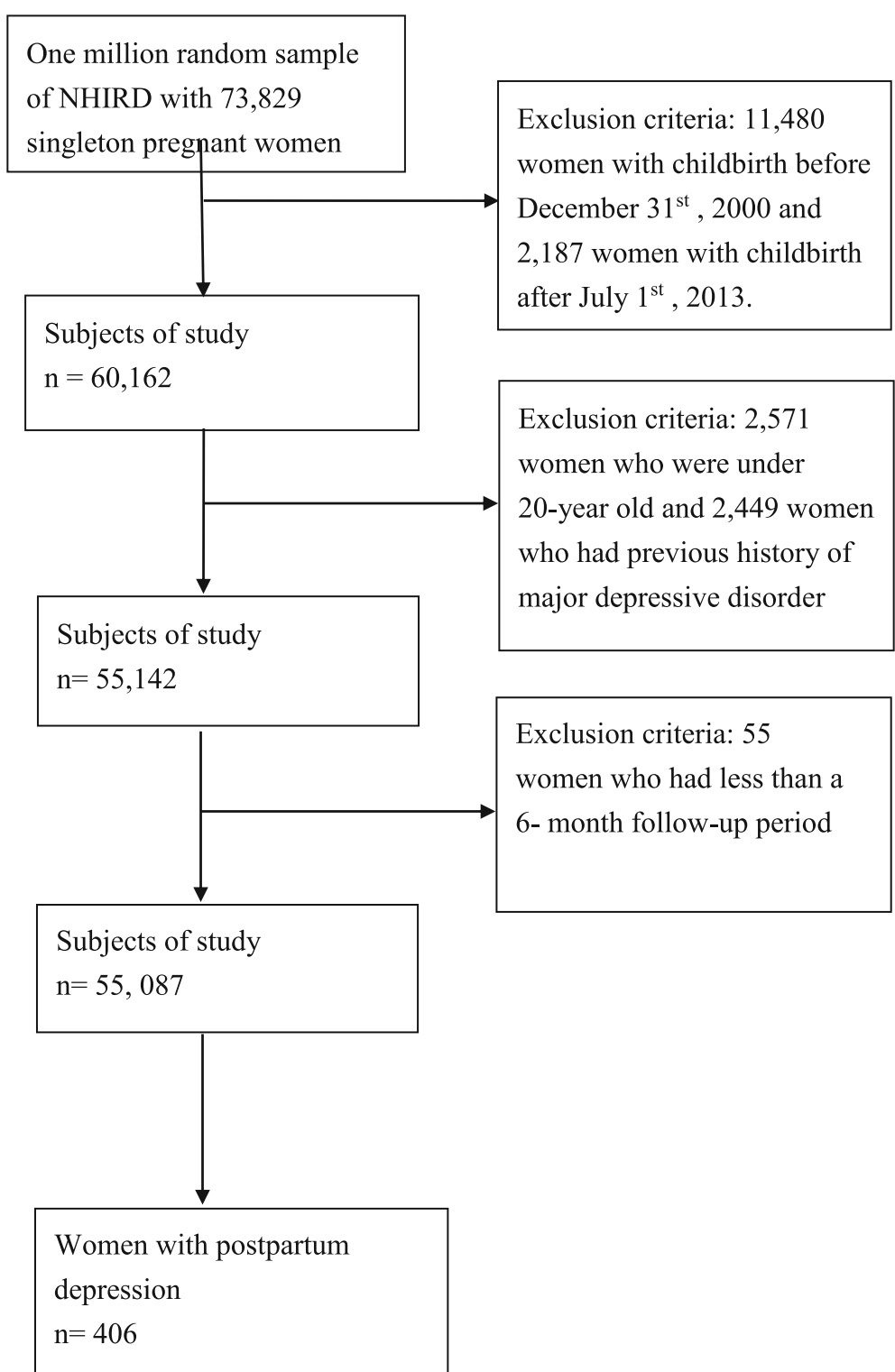

Fig. 1 Flowchart of the collection of subjects from the Longitudinal Health Insurance Database2000 (LHID2000), a sub-dataset of National Health Insurance Research Database (NHIRD), from January 2000 to December 2013

\section{Statistical analysis}

We used the Microsoft ${ }^{\oplus}$ SQL Server 2008 to calculate and manage the patients' baseline data. The IBM SPSS statistics software v20 (IBM SPSS, 2013) was used for further data analysis. All the variables were calculated as percentages. Standard deviations and mean values were determined for the quantitative variables. Statistical significance was determined using Student's T test and the Chi-square test. Multivariate logistic regression analysis was used to determine any associations between antepartum UTIs, PPD, and additional factors. We selected risk factors into further multivariate logistic regression analysis by which total $n \geqq 5$ in the PPD group.
A two-sided $p$-value $<0.05$ was regarded as statistically significant in all statistical tests.

\section{Results}

\section{Demographics}

Data for a total of 55,087 women who had singleton pregnancies between January 2001 and June 2013 was utilized in this study, including data for a total of 406 women who were newly diagnosed with PPD in the first 6 months postpartum. All the singleton pregnancy women were divided into two groups: a PPD group $(n=406)$ and a non-PPD group $(n=54,691)$. Table 1 shows the demographic characteristics of the two 
Table 1 Demographic characteristics of study populations in Taiwan from 2000 to 2013

\begin{tabular}{|c|c|c|c|c|}
\hline Demographic factor & $\begin{array}{l}\text { Total pregnant } \\
\text { women } n(\%)\end{array}$ & $\begin{array}{l}\text { Without PPD } \\
n(\%)\end{array}$ & PPD $n(\%)$ & $P$ value $^{a}$ \\
\hline No. of patients & 55,087 & 54,681 & 406 & \\
\hline $\begin{array}{l}\text { Age (mean } \pm \text { standard deviation, } \\
\text { years) }\end{array}$ & $30 \pm 6.2$ & $29.9 \pm 6.1$ & $31.9 \pm 10.4$ & 0.003 \\
\hline Age_group & & & & $<0.001^{* *}$ \\
\hline $20-24$ & 7986(14.5) & $7928(14.5)$ & $58(14.3)$ & \\
\hline $25-29$ & $19,548(35.5)$ & $19,405(35.5)$ & 143(35.2) & \\
\hline $30-34$ & $19,092(34.7)$ & $18,968(34.7)$ & 124(30.5) & \\
\hline $35-39$ & $6724(12.2)$ & $6679(12.2)$ & $45(11.1)$ & \\
\hline$\geqq 40$ & 1737(3.1) & 1701(3.1) & $36(8.9)$ & \\
\hline $\begin{array}{l}\text { Hospital stay (mean } \pm \text { standard } \\
\text { deviation) }\end{array}$ & $4.8 \pm 2.2$ & $4.8 \pm 1.6$ & $4.2 \pm 3.2$ & \\
\hline Monthly income (TWD ${ }^{b}$ ) & & & & $<0.05^{*}$ \\
\hline$<20,000$ & $36,586(66.4)$ & $36,292(66.4)$ & 294(72.4) & \\
\hline $20,000-40,000$ & $14,340(26.0)$ & $14,246(26.1)$ & $94(23.2)$ & \\
\hline $40,000-60,000$ & $3687(6.7)$ & $3670(6.6)$ & $17(4.2)$ & \\
\hline$\geqq 60,000$ & $474(0.9)$ & $473(0.9)$ & $1(0.2)$ & \\
\hline \multicolumn{5}{|l|}{$\begin{array}{l}\text { Antepartum urinary tract } \\
\text { infection }\end{array}$} \\
\hline Yes & $7325(13.3)$ & $7255(13.3)$ & $70(17.2)$ & $<0.05^{*}$ \\
\hline Upper & $255(0.5)$ & $249(0.5)$ & $6(1.5)$ & $<0.05^{*}$ \\
\hline Lower & $7070(12.9)$ & $7006(12.9)$ & $64(16)$ & $<0.05^{*}$ \\
\hline No & $47,762(86.7)$ & $47,426(86.7)$ & 336(82.8) & \\
\hline \multicolumn{5}{|l|}{ Co-morbidity disease } \\
\hline Antepartum hemorrhage & $460(0.8)$ & $456(0.8)$ & $4(1.0)$ & 0.739 \\
\hline Premature separation of placenta & $320(0.6)$ & $316(0.6)$ & $4(1.0)$ & 0.282 \\
\hline Placenta previa & 854(1.6) & $849(1.6)$ & $5(1.2)$ & 0.602 \\
\hline Eclampsia or pre-eclampsia & $799(1.5)$ & $792(1.4)$ & $7(1.7)$ & 0.643 \\
\hline Unstable lie & $47(0.1)$ & $47(0.1)$ & 0 & - \\
\hline Polyhydramnios & $37(0.1)$ & $37(0.1)$ & 0 & - \\
\hline Oligohydramnios & $4118(7.5)$ & $4082(7.5)$ & $36(8.9)$ & 0.285 \\
\hline Poor fetal growth & $521(0.9)$ & $518(0.9)$ & $3(0.7)$ & 0.666 \\
\hline Excessive fetal growth & $532(1.0)$ & $526(1.0)$ & $6(1.5)$ & 0.290 \\
\hline Cervical incompetence & $56(0.1)$ & $56(0.1)$ & 0 & - \\
\hline Premature birth & $3648(6.6)$ & $3615(6.6)$ & $33(8.1)$ & 0.221 \\
\hline Chronic pulmonary disease & 1383(2.5) & $1366(2.5)$ & $17(4.2)$ & $<0.05^{*}$ \\
\hline Hypertension & 879(1.6) & $860(1.6)$ & 19(4.7) & $<0.001^{* *}$ \\
\hline $\begin{array}{l}\text { Hypertension-complicated } \\
\text { pregnancy }\end{array}$ & $1151(2.1)$ & $1140(2.1)$ & $11(2.7)$ & 0.381 \\
\hline $\begin{array}{l}\text { Diabetes complicating pregnancy } \\
\text { childbirth }\end{array}$ & 2655(4.8) & $2636(4.8)$ & $19(4.7)$ & 0.895 \\
\hline Hyperlipidemia & $321(0.6)$ & $314(0.6)$ & $7(1.7)$ & $<0.05^{*}$ \\
\hline Heart disease & $1551(2.8)$ & 1517(2.8) & $34(8.4)$ & $<0.001^{* *}$ \\
\hline Anemia & $5872(10.7)$ & $5824(10.7)$ & 48(11.8) & 0.446 \\
\hline Cerebrovascular disease & $250(0.5)$ & $240(0.4)$ & $10(2.5)$ & $<0.001^{* *}$ \\
\hline Parkinson disease & $24(0.04)$ & $20(0.03)$ & $4(1.0)$ & $<0.001^{* *}$ \\
\hline
\end{tabular}


Table 1 Demographic characteristics of study populations in Taiwan from 2000 to 2013 (Continued)

\begin{tabular}{|c|c|c|c|c|}
\hline Demographic factor & $\begin{array}{l}\text { Total pregnant } \\
\text { women } n(\%)\end{array}$ & $\begin{array}{l}\text { Without PPD } \\
n(\%)\end{array}$ & PPD $n(\%)$ & $P$ value ${ }^{\mathrm{a}}$ \\
\hline Epilepsy & $112(0.2)$ & $108(0.2)$ & $4(1.0)$ & $<0.001^{* *}$ \\
\hline Tuberculosis & $59(0.1)$ & $59(0.1)$ & 0 & - \\
\hline Asthma & 892(1.6) & $883(1.6)$ & $9(2.2)$ & 0.338 \\
\hline Chronic kidney disease & $145(0.3)$ & $140(0.3)$ & $5(1.2)$ & $<0.001^{* *}$ \\
\hline
\end{tabular}

a. $p$-values are two-sided

b TWD refers to New Taiwan dollars, of which 1 US dollar = 30TWD

${ }^{* *} p<0.001,{ }^{*} p<0.05$

study groups. Women with PPD had older ages (31.9 \pm 10.4 years, $p<0.001$ ) compared with the non-PPD group. There were many antepartum comorbidities that were found to be significantly associated with PPD, including chronic pulmonary disease, hypertension, peptic ulcer disease, chronic kidney disease, liver cirrhosis, hypertensioncomplicated pregnancy, heart disease, asthma, epilepsy, early delivery onset, premature birth, and UTI. Both upper and lower tract UTIs showed significant associations with PPD. The average hospital stay of all the women for childbirth was $4.8 \pm 2.2$ days. The average time to PPD diagnosis was $88.0 \pm 51.0$ days after delivery.

\section{Multivariable logistic regression analysis of postpartum depression}

Table 2 shows the logistic regression analysis results for certain risk factors of PPD. A monthly income of less than NT\$ 20,000 and aged 20-24 were used as the reference. Heart disease (aOR $1.95(1.26,3.02), p<0.001)$, antepartum UTI (aOR $1.27(1.07,1.65), p<0.05)$, and age $\geqq 40$ (aOR $1.98(1.20,3.29), p<0.01)$ were all significant risk factors of PPD.

Among all antepartum UTIs, upper tract UTIs (aOR 2.97 $(1.31,6.77))$ had a higher OR than lower tract UTIs (aOR $1.21(1.02,1.58))$. In addition, the aOR of monthly income NT\$40,000-60,000 was 0.59 ((0.36, 0.97), $p<0.05)$.

\section{Discussion}

This is the first study that has focused on the relationship between antepartum UTIs and PPD. The results of this 14-year population based study show that antepartum UTIs are significantly associated with PPD. In addition, women with upper antepartum UTIs had near 3 -fold greater risk of PPD than normal groups (aOR 2.97(1.31, 6.77)).

According to the study results, chronic kidney disease, epilepsy, heart disease, and upper UTI are the four greatest risk factors for PPD. These findings are consistent with those of previous studies that have also found that chronic kidney disease, epilepsy, and heart disease are associated with major depressive disorder or PPD [22-28]. In fact, the relationship between chronic kidney disease and major depressive disorder is well documented
[22-24], with the decreased quality of life caused by chronic kidney disease having been found to affect mental health in both men and women [24]. Similarly, the relationship between epilepsy and higher rates of PPD is well documented [25-27]. Meanwhile, a prospective study revealed that the rate of neonatal complications is significantly higher in women with heart disease [28]. Therefore, it is reasonable that PPD is related to antepartum heart disease.

UTIs are among the most common bacterial infections in women, affecting approximately $10 \%$ of women. A previous study showed that $2-10 \%$ of pregnant women had suffered from a UTI [8], while another study found that $10 \%$ of all antepartum admissions were due to UTIs [29]. The higher UTI rate is caused by anatomical and physiological changes to the urinary tract system due to pregnancy [30]. Furthermore, pregnancy also causes asymptomatic bacteriuria changes to symptomatic UTI and reinfection [31].

The symptoms accompanying a UTI include urinary frequency and urgency, painful urination, and lower abdomen discomfort. Overactive bladder syndrome shares some of the same symptoms as UTIs, including urinary frequency and urgency, as well as urgency incontinence. In nonpregnant women, an association between overactive bladder syndrome and major depressive disorder has previously been reported [32-36]. Relatedly, van de Pol et al. demonstrated a significant relationship between PPD and overactive bladder syndrome [37]. Pregnant women who experience urinary frequency and urgency due to a UTI or overactive bladder syndrome may be embarrassed to talk about these symptoms with their physicians, which may further increase the mental stress experienced by these women. Abdollahi et al. demonstrated that recurrent UTIs are associated with PPD, but they did not further examine the relationship with respect to upper and lower UTIs [38].

Antepartum UTIs and PPD have several common risk factors such as obstetric, pediatric, and socioeconomic factors. Mazor-Dray et al. demonstrated that maternal UTIs are associated with preterm delivery, preeclampsia, intra-uterine growth restriction, and cesarean delivery [12]. Furthermore, the rates of PPD have been found to be as high as $40 \%$ among women with premature delivery [39], while Yang et al. demonstrated that cesarean delivery, preterm delivery, and preeclampsia were associated with 
Table 2 The association between PPD and certain risk factors (in which total $n \geqq 5$ in the PPD group) analyzed by multivariate logistic regression model

\begin{tabular}{lllll}
\hline & Crude odds ratio & $95 \%$ Confidence Interval & Adjusted odds ratio & 95\% Confidence Interval \\
\hline Antepartum UTI & 1.36 & $(1.05,1.76)^{\mathrm{a}}$ & 1.27 & $(1.07,1.65)^{\mathrm{a}}$ \\
Upper UTI & 3.28 & $(1.45,7.41)^{\mathrm{b}}$ & 2.97 & $(1.31,6.77)^{\mathrm{b}}$ \\
Lower UTI & 1.29 & $(1.04,1.68)^{\mathrm{a}}$ & 1.21 & $(1.02,1.58)^{\mathrm{a}}$
\end{tabular}

Age group (reference: $20-24)$

$\begin{array}{rl}20-24 & 1 \\ 25-29 & 1.00 \\ 30-34 & 0.89 \\ 35-39 & 0.92 \\ \geqq 40 & 2.89\end{array}$

$(0.74,1.37)$

$(0.65,1.22)$

$(0.62,1.36)$

$(1.90,4.40)^{c}$

$(0.65,1.03)$

$(0.35,0.93)^{\mathrm{a}}$

$(0.37,1.86)$

$\geqq 60,000$

Co-morbidity disease

Chronic pulmonary disease $\quad 1.71$

Hypertension

Hyperlipidemia

Heart disease

Cerebrovascular disease

Chronic kidney disease

Note 1. a: $p<0.05, \mathrm{~b}: p<0.01, \mathrm{c}: p<0.00$

Note 2. TWD refers to New Taiwan dollars, of which 1 US dollar $=30$ TWD

the development of PPD [21]. That being said, preeclampsia was not shown to be associated with PPD in our study. Otherwise, women of low socioeconomic status have a five-fold greater incidence of bacteriuria than normal populations. Low socioeconomic status has also been found to be a risk factor for both antepartum UTIs [40, 41] and PPD [42, 43], while antepartum UTIs are an independent risk factor of PPD.

In our study, upper antepartum UTIs had a higher aOR (OR $2.97(1.31,6.77))$ than lower UTIs. Upper antepartum UTIs are more common during the second half of pregnancy [44], are the most common severe complication of pregnancy [28], and cause approximately $12 \%$ of pregnancy associated sepsis complications that result in admission to an obstetric intensive care unit [45]. Approximately $20 \%$ of upper UTIs in pregnant women will lead to sepsis and multiple-system failure from endotoxemia [44, 46]. Upper antepartum UTIs reduce physical strength and increase mental stress in pregnant women. In addition, upper antepartum UTIs has 2.97fold risk of preterm delivery [47], which is another important risk factor of PPD [21].

This study was a retrospective population-based study. Some data that can be useful in determining the severity of a UTI, such as the bacterial species involved, laboratory findings, asymptomatic bacteriuria status, and the side of pyelonephritis, were not available in the NHIRD. In addition, the number of upper and lower antepartum UTI patients in the study was relatively limited. Moreover, we collected PPD patients by coding ICD-9-CM coded which were diagnosed by psychiatrists who have individual concerns about PPD diagnosis. The incidence of PPD in the study cohort may have been underestimated as some women who experience depression after delivery do not seek medical help. Large-scale, prospective studies are needed to further evaluate the association between antepartum UTIs and PPD.

\section{Conclusions}

The results of this study demonstrate that antepartum UTIs, particularly upper antepartum UTIs, are significantly associated with PPD. Specifically, women with upper antepartum UTIs had 2.97-fold increased risk of PPD. As UTIs are among the most common bacterial infections in pregnant women, our results provide useful information for gynecologists, obstetricians, and health policy planners. Above all, they indicate that these health care professionals should pay greater attention to the mental health of mothers who have suffered upper UTIs during their pregnancies. 


\section{Abbreviations}

CCl: Charlson comorbidity index; ICD-9-CM: International classification of diseases, 9th revision, clinical modification; LHID 2000: Longitudinal health insurance database 2000; NHIRD: National health insurance research database; OR: Odds ratio; PPD: Postpartum depression; UTI: Urinary tract infection

\section{Acknowledgments}

The implications and conclusions of this study do not represent the opinions of the Bureau of National Health Insurance, the Department of Health, or the National Health Research Institute.

\section{Funding}

This work was supported by grants from the Ministry of Science and Technology Taiwan (MOST 104-2320-B-016 -012 -MY3), the Tri-Service General Hospital of Taipei, Taiwan (TSGH-106-148 and TSGH-107-104-2320B-016012-MY3), the grants from the Taoyuan General Hospital, Ministry of Health and Welfare (PYT10702), and the Teh-Tzer Study Group for Human Medical Research Foundation (A1061082). The funders had no role in the study design, data collection, analysis, decision to publish, or preparation of the manuscript.

\section{Availability of data and materials}

We are unable to share our data, as the National Health Insurance program of Taiwan limits access to the National Health Insurance Research Database only to approved applicants.

\section{Authors' contributions}

JML wrote the proposal and prepared the manuscript. YPL contributed the conception and design of the manuscript. FWC revised the manuscript. SPC conducted the data analysis. HHC and SPC collected the data and helped prepare the manuscript. RJH prepared the manuscript and data analysis. JJY revised the manuscript. $\mathrm{RJH}$ revised the manuscript and data analysis. All the authors read and approved the final manuscript.

\section{Ethics approval and consent to participate}

This study was approved by the Institutional Review Board of the Tri-Service General Hospital (approval No: B-104-20, Taipei, Taiwan).

\section{Consent for publication}

Not applicable.

\section{Competing interests}

The authors declare that they have no competing interests.

\section{Publisher's Note}

Springer Nature remains neutral with regard to jurisdictional claims in published maps and institutional affiliations.

\section{Author details}

'Division of Urology, Department of Surgery, Taoyuan General Hospital, Ministry of Health and Welfare, Taoyuan, Taiwan. ${ }^{2}$ Department of Medicine, National Yang-Ming University, Taipei, Taiwan. ${ }^{3}$ Graduate Institute of Life Sciences, National Defense Medical Center, Taipei, Taiwan. ${ }^{4}$ American-Sino Women's \& Children's, Hospital (SongYuan), Shanghai City, China. ${ }^{5}$ Lihuili Eastern Hospital, Ningbo Medical Center, Ningbo City, Zhejiang province, China. ${ }^{6}$ Department of emergency Medicine, National Taiwan University Hospital, Taipei, Taiwan. ${ }^{7}$ Division of Genetics and endocrinology, Chang Gung Children's Hospital, Taoyuan, Taiwan. ${ }^{8}$ Division of Urology, Department of Surgery, Yumin medical corporation Yumin hospital, Nantou, Taiwan. ${ }^{9}$ Department of Psychiatry, Cardinal Tien Hospital, New Taipei City, Taiwan.

${ }^{10}$ Institute of Biomedical Engineering, College of Medicine and College of Engineering, National Taiwan University, Taipei, Taiwan. ${ }^{11}$ Superintendent, Tri-Service General Hospital Penghu Branch, National Defence Medical Center, Penghu Branch, Taiwan. ${ }^{12}$ Biobank Management Center of the Tri-Service General Hospital, National Defense Medical Center, Taipei, Taiwan. ${ }^{13}$ Department of Pathology and Graduate Institute of Pathology and Parasitology, the Tri-Service General Hospital, National Defense Medical Center, No. 161, Sec. 6, Minquan E. Road, Neihu District, Taipei 114, Taiwan.
Received: 25 July 2016 Accepted: 27 February 2018

Published online: 27 March 2018

\section{References}

1. O'Hara MW, Schlechte JA, Lewis DA, Varner MW. Controlled prospective study of postpartum mood disorders: psychological, environmental, and hormonal variables. J Abnorm Psychol. 1991;100(1):63.

2. Stowe ZN, Nemeroff CB. 1995. Women at risk for postpartum-onset major depression. Am J Obstet Gynecol. 1995;173(2):639-45.

3. Lee DT, Yip AS, Chiu HF, Leung TY, Chung TK. A psychiatric epidemiological study of postpartum Chinese women. Am J Psychiatry. 2001;158(2):220-6.

4. APA. Diagnostic and statistical manual of mental disorders DSM-V. Washington, DC: American Psychiatric Association; 2013.

5. O'Hara MW A, McCabe JE. Postpartum depression: current status and future directions. Annu Rev Clin Psychol. 2013;9:379-407.

6. Chang FW, Lee WY, Liu YP, Yang JJ, Chen SP, Cheng KC, Lin YC, Ho TW, Chiu FH, Hsu RJ, et al. The relationship between economic conditions and postpartum depression in Taiwan: a nationwide population-based study. J Affect Disord. 2016;204:174-9.

7. Huang YC, Mathers N. Postnatal depression - biological or cultural? A comparative study of postnatal women in the UK and Taiwan. J Adv Nurs. 2008;33:279-87.

8. Robertson E, Grace $S$, Wallington T, Stewart DE. Antenatal risk factors for postpartum depression: a synthesis of recent literature. Gen Hosp Psychiatry. 2004;26(4):289-95

9. Norhayati MN, Hazlina NN, Asrenee AR, Emilin WW. Magnitude and risk factors for postpartum symptoms: a literature review. J Affect Disord. 2015; 175:34-52.

10. Le J, Briggs GG, McKeown A, Bustillo G. Urinary tract infections during pregnancy. Ann Pharmacother. 2004;38(10):1692-701.

11. Lee $M$, Bozzo $P$, Einarson A, Koren $G$. Urinary tract infections in pregnancy. Can Fam Physician. 2008:54:853-4.

12. Mazor-Dray E, Levy A, Schlaeffer F, Sheiner E. Maternal urinary tract infection: is it independently associated with adverse pregnancy outcome? J Matern Fetal Neonatal Med. 2009:22(2):124-8.

13. Sheffield JS, Cunningham FG. Urinary tract infection in women. Obstet Gynecol. 2005;106(5):1085-92.

14. Chen JY, Liu JM, Chang FW, Chang H, Cheng KC, Yeh CL, Wei YF, Hsu RJ Scabies increased the risk and severity of COPD: a nationwide populationbased study. Int J Chron Obstruct Pulmon Dis. 2016;11:2171-8.

15. Liu JM, Lin PH, Hsu RJ, Chang YH, Cheng KC, Pang ST, Lin SK Complementary traditional Chinese medicine therapy improves survival in patients with metastatic prostate cancer. Medicine. 2016:95(31):e4475.

16. Liu JM, Wang HW, Chang FW, Liu YP, Chiu FH, Lin YC, Cheng KC, Hsu RJ. The effects of climate factors on scabies. A 14-year population-based study in Taiwan. Parasite. 2016;23:54

17. Hsing AW, loannidis JP. Nationwide population science: lessons from the Taiwan National Health Insurance Research Database. JAMA Intern Med. 2015;175(9):1527-9.

18. National Health Insurance Institutes: National Health Insurance Research Database. http://nhird.nhri.org.tw/en/Data_Subsets.html\# Accessed 10 Oct 2016.

19. Liu JM, Chiu FH, Lin CY, Chang FW, Hsu RJ. Incidence of autoimmune diseases in patients with scabies: a nationwide population-based study in Taiwan. Rheumatol Int. 2017;37(7):1125-34.

20. Yang SN, Shen LJ, Ping T, Wang YC, Chien CW. The delivery mode and seasonal variation are associated with the development of postpartum depression. J Affect Disord. 2011;132(1):158-64.

21. Lin CY, Chang FW, Yang JJ, Chang CH, Yeh CL, et al. Increased risk of bipolar disorder in patients with scabies: a nationwide population-based matched-cohort study. Psychiatry Res. 2017;257:14-20.

22. Hedayati SS, Minhajuddin AT, Afshar M, Toto RD, Trivedi MH, Rush AJ. Association between major depressive episodes in patients with chronic kidney disease and initiation of dialysis, hospitalization, or death. JAMA. 2010:303(19):1946-53.

23. Zalai D, Szeifert L, Novak M. Psychological distress and depression in patients with chronic kidney disease. Semin Dial. 2012;25(4):428-38.

24. Abdel-Kader K, Unruh ML, Weisbord SD. Symptom burden, depression, and quality of life in chronic and end-stage kidney disease. Clin J Am Soc Nephrol. 2009;4(6):1057-64 
25. Turner K, Piazzini A, Franza A, Fumarola C, Chifari R, Marconi AM, et al. Postpartum depression in women with epilepsy versus women without epilepsy. Epilepsy Behav. 2006;9(2):293-7.

26. Galanti M, Newport DJ, Pennell PB, Titchner D, Newman M, Knight BT, et al. Postpartum depression in women with epilepsy: influence of antiepileptic drugs in a prospective study. Epilepsy Behav. 2009;16(3):426-30.

27. Turner K, Piazzini A, Franza A, Marconi AM, Canger R, Canevini MP. Epilepsy and postpartum depression. Epilepsia. 2009;50(Suppl 1):24-7.

28. Siu SC, Sermer M, Colman JM, Alvarez AN, Mercier LA, Morton BC, et al. Cardiac disease in pregnancy (CARPREG) investigators. Prospective multicenter study of pregnancy outcomes in women with heart disease. Circulation. 2001;104(5):515-21.

29. Bacak SJ, Callaghan WM, Dietz PM, Crouse C. Pregnancy-associated hospitalizations in the United States, 1999-2000. Am J Obstet Gynecol. 2005:192(2):592-7.

30. Nowicki B. Urinary tract infection in pregnant women: old dogmas and current concepts regarding pathogenesis. Curr Infect Dis Rep. 2002;4:529-35.

31. Foxman B, Brown P. Epidemiology of urinary tract infections: transmission and risk factors, incidence, and costs. Infect Dis Clin N Am. 2003;17:227-41.

32. Zorn BH, Montgomery H, Pieper K, Gray M, Steers WD. Urinary incontinence and depression. J Urol. 1999;162:82-4.

33. Buchsbaum GM, Chin M, Glantz C, Guzick D. Prevalence of urinary incontinence and associated risk factors in a cohort of nuns. Obstet Gynecol. 2002;100:226-9.

34. Chiverton PA, Wells TJ, Brink CA, Mayer R. Psychological factors associated with urinary incontinence. Clin Nurse Spec. 1996;10:229-33.

35. Stewart WF, Van Rooyen JB, Cundiff GW, Abrams P, Herzog AR, Corey R, et al. Prevalence and burden of overactive bladder in the United States. World J Urol. 2003;20:327-36.

36. Melville JL, Delaney K, Newton K, Katon W. Incontinence severity and major depression in incontinent women. Obstet Gynecol. 2005;106:585-92.

37. van de Pol G, van Brummen HJ, Bruinse HW, Heintz AP, van der Vaart CH. Is there an association between depressive and urinary symptoms during and after pregnancy? Int Urogynecol J Pelvic Floor Dysfunct. 2007;18(12):1409-15.

38. Abdollahi F, Zarghami M, Azhar MZ, Sazlina SG, Lye MS. Predictors and incidence of post-partum depression: a longitudinal cohort study. J Obstet Gynaecol Res. 2014;40(12):2191-200

39. Vigod SN, Villegas L, Dennis CL, Ross LE. Prevalence and risk factors for postpartum depression among women with preterm and low-birth-weight infants: a systematic review. BJOG. 2010;117(5):540-50.

40. Turck M, Goffe BS, Petersdorf RG. Bacteriuria of pregnancy. Relation to socioeconomic factors. N Engl J Med. 1962;266:857-60.

41. Golan A, Wexler S, Amit A, Gordon D, David MP. Asymptomatic bacteriuria in normal and high-risk pregnancy. Eur J Obstet Gynecol Reprod Biol. 1989; 33:101-8.

42. Inandi T, Bugdayci R, Dundar P, Sumer H, Sasmaz T. Risk factors for depression in the first postnatal year: a Turkish study. Soc Psychiatry Psychiatr Epidemiol. 2005;40:725-30

43. Ozdemir H, Ergin N, Selimoglu K, Bilgel N. Postnatal depressive mood in Turkish women. Psychol Health Med. 2014;10:96-107.

44. Hill JB, Sheffield JS, McIntire DD, Wendel GD Jr. Acute pyelonephritis in pregnancy. Obstet Gynecol. 2005;105:18-23.

45. Zeeman GG, Wendel GD, Cunningham FG. A blueprint for obstetric critical care. Am J Obstet Gynecol. 2003;188(2):532-6.

46. Cunningham FG, Morris GB, Mickal A. Acute pyelonephritis of pregnancy: a clinical review. Obstet Gynecol. 1973;42(1):112-7.

47. Farkash E, Weintraub AY, Sergienko R, Wiznitzer A, Zlotnik A, Sheiner E. Acute antepartum pyelonephritis in pregnancy: a critical analysis of risk factors and outcomes. Eur J Obstet Gynecol Reprod Biol. 2012;162(1):24-7.

\section{Submit your next manuscript to BioMed Central and we will help you at every step:}

- We accept pre-submission inquiries

- Our selector tool helps you to find the most relevant journal

- We provide round the clock customer support

- Convenient online submission

- Thorough peer review

- Inclusion in PubMed and all major indexing services

- Maximum visibility for your research

Submit your manuscript at www.biomedcentral.com/submit
Biomed Central 